\title{
Kafe sebagai Gaya Hidup Masyarakat Konsumerisme (Studi Kasus pada Starbucks)
}

\author{
Mendy Hosiana Melkisedek \\ Program Studi Desain Komunikasi Visual, Fakultas Seni dan Desain, \\ Universitas Kristen Petra, Surabaya, Indonesia \\ E-mail: mendy@petra.ac.id
}

\begin{abstract}
Abstrak
Akhir-akhir ini perubahan sosial terjadi pada masyarakat kota besar di Indonesia seiring berkembangnya teknologi dan informasi yang begitu cepat. Pola hidup masyarakat kota besar kian bersifat konsumtif akibat serangkaian iklan televisi atau pun sosial media yang menawarkan berbagai produk yang dimaknai secara simbolik. Pola konsumtif masyarakat kini tak hanya sekedar bertujuan untuk pemenuhan kebutuhan dasar atau nilai guna dari produk yang dibeli tetapi lebih pada nilai dan prestise yang didapatkan dengan membeli produk tersebut. Dalam makalah ini akan dibahas mengenai perilaku konsumerisme masyarakat kota terhadap kafe ditinjau dari teori konsumerisme dan fetisisme komoditi.
\end{abstract}

Kata kunci: Kafe, konsumerisme, fetisisme komoditi.

\begin{abstract}
Lately, as technology and information rapidly develop, social change has occurred in large urban communities in Indonesia. The life pattern of the big city people is increasingly consumptive due to a series of television advertisements or social media that offer a variety of products that are symbolically interpreted. The consumptive pattern of the community is now not only to fulfill the basic needs or the usefulness of the product purchased but rather the value and prestige gained by buying the product. This paper will discuss about the behavior of urban society's consumerism towards kafes according to the theory of consumerism and commodity fetishism.
\end{abstract}

Keywords: Kafe, consumerism, commodity fetishism.

\section{Pendahuluan}

Perkembangan teknologi dan informasi yang tak lain adalah tiang penopang kapitalisme perekonomian di Barat saat ini membanjiri masyarakat perkotaan dan memaksa terjadinya transformasi pola pikir dan gaya hidup masyarakat perkotaan. Berbagai media seperti televisi, internet, sosial media berlomba-lomba hadir untuk menawarkan berbagai macam tontonan hiburan dan juga informasi bagi masyarakat. Sehingga perilaku masyarakat tanpa sadar terbentuk dari berbagai macam informasi dari tontonan yang mereka saksikan tersebut. Pembangunan citra diri masyarakat melalui media-media massa ini membangun pengalaman dalam satu ruang dan waktu yang membatasi yang disebut realitas semu (Yasraf, 2010).

Seperti terhipnotis oleh kemuktahiran yang ada saat ini, identitas masyarakat tercermin melalui pemaknaan simbolik dari penggunaan produkproduk yang sarat akan kecanggihan teknologi dan informasi. Gaya hidup masyarakat menjadi gaya hidup konsumerisme yang tak lagi mementingkan nilai guna suatu produk tetapi bagaimana produk tersebut dapat meningkatkan citra diri, prestise penggunanya di hadapan khalayak. Masyarakat cenderung memaknai penggunaan produk seperti pakaian, mobil, sepatu, bahkan makanan dan minuman sebagai pembentukan simbol sosial dan identitas kultural.

Kopi adalah salah satu minuman yang digemari masyarakat di dunia. Budaya minum kopi bukan saja dinikmati oleh masyarakat Indonesia tetapi juga di berbagai negara lain. Umumnya budaya minum kopi di Indoensia dilakukan sambil membaca koran di pagi hari sebelum memulai aktivitas atau di sore hari saat berkumpul bersama seluruh keluarga. Akan tetapi keterbatasan waktu oleh aktivitas perkotaan yang padat membuat tradisi ini menjadi memudar.

Bagi masyarakat konsumer, minuman kopi sebagai objek konsumsi tidak lagi dipandang dari nilai guna atau kebutuhan dasar individu itu 
untuk mengkonsumsi kopi, tetapi juga dipandang sebgai medium untuk mencitrakan dirinya. Bukan seberapa enak rasa kopi itu tetapi pandangan tentang kopi apa yang diminum, di mana seseorang itu minum kopi dan bersama siapa itulah yang membangun suatu citra individu konsumer. Berada di sebuah kafe ternama dalam sebuah mall dapat dimaknai secara simbolik untuk menandai status sosial, ekonomi dan prestise seseorang. Hal ini menjadi suatu budaya baru yakni budaya populer.

Kata "kafe" atau "café" tentu tak asing lagi bagi masyarakat kota besar. Kafe sendiri memiliki makna sebuah kedai kecil yang menjajakan segala jenis minuman kopi. Namun dalam perkembangannya, kafe saat ini tak sekedar kedai penyedia minuman kopi tetapi juga didesain begitu rupa dengan berbagai tema dan keunikan serta berbagai fasilitas penunjang untuk menarik para konsumennya. Banyak kafe di ibukota yang sengaja mengundang band-band ternama untuk tampil menemani para konsumen minum kopi dan bersantai. Ada juga yang melengkapi kafe dengan fasilitas wi-fi dan stop kontak bagi para konsumen agar dapat sekaligus mengerjakan tugas atau pekerjaannya dengan laptop atau i-pad-nya.

\section{Tradisi Minum Kopi di Indonesia}

Indonesia yang terkenal sebagai salah satu negara penghasil dan pengekspor kopi di dunia, memiliki banyak jenis kopi yang berkualitas. Salah satu kopi yang terkenal adalah kopi Arabica dari sumatera dan kopi luwak (http://www.kopisiana. com).

Hal ini menunjang tradisi minum kopi di masyarakat Indonesia. Minum kopi atau 'ngopi' adalah salah satu tradisi turun temurun yang diwarisi oleh masyarakat Indonesia. Sebagian masyarakat terbiasa minum kopi di pagi hari, sebelum memulai aktivitas bekerja. Namun, ada pula yang meminum kopi di sore/malam hari bersama keluarga, untuk melepas penat setelah bekerja seharian. (nationalgeographic.co.id). Umumnya budaya minum kopi ini juga ditemani dengan kudapan seperti kue atau roti.

Budaya minum kopi Pada waktu-waktu ini, kedai kopi juga akan ramai pengunjung. Masyarakat biasa menikmati kopi sembari bersosialisasi dengan kawan-kawannya atau sekadar bersantai.

\section{Starbucks}

Salah satu kafe ternama yang tak asing lagi bagi masyarakat kota-kota besar di Indonesia adalah
Starbucks yang merupakan kafe khusus yang menyajikan berbagai minuman kopi bertaraf internasional dan memiliki banyak cabang di hampir seluruh belahan dunia, termasuk di Indonesia. Umumnya gerai Starbucks berlokasi di pusat-pusat perbelanjaan besar. Kafe yang memulai kiprahnya sejak tahun 1971 ini berawal dari etalase sempit di Seattle's historic Pike Place Market, Starbucks menawarkan beberapa biji kopi terbaik di dunia. Dua hal yang ingin selalu diharapkan yakni berbagi kopi yang berkualitas dengan sesama dan membuat dunia menjadi lebih baik.

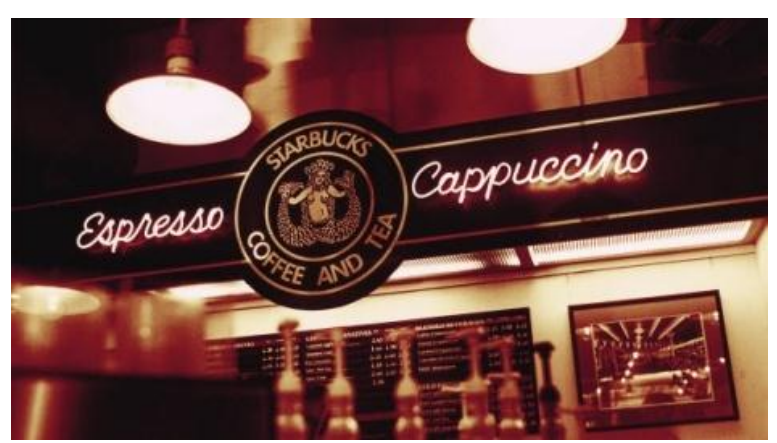

Gambar 1. Starbucks di awal berdirinya

Pada tahun 1981, Howard Schultz selaku Starbucks chairman, president and chief executive officer pertama kali masuk ke toko Starbucks. Dari cangkir pertama Sumatra, Howard tertarik ke Starbucks dan bergabung setahun kemudian. Keterpikatan pada sebuah kedai kopi ketika ia melakukan perjalanan ke Italia tahun 1983 memunculkan visi untuk membawa tradisi kedai kopi Italia tersebut ke Amerika Serikat. Sebuah konsep kedai kopi sebagai ruang ke tiga antara rumah dan kantor yang menawarkan tempat untuk bercakap-cakap dan bersantai bersama komunitas. Sejenak Howard meninggalkan Starbucks untuk membuka kedai kopi II Giornale miliknya sendiri pada tahun 1985 dan pada Agustus 1987, Howard kembali untuk membeli Starbucks dengan bantuan investor lokal. (www.starbucks.com)

Sejak awal, Starbucks dibentuk dengan konsep yang berbeda dengan kafe-kafe lainnya. Tidak hanya diciptakan untuk sekedar merayakan tradisi minum kopi dengan menyajikan kopi-kopi berkualitas di dunia, tetapi lebih difokuskan pada perasaan kebersamaan yang saling terkait. Misinya adalah menginspirasi dan menumbuhkan semangat manusia - satu orang, satu cangkir, dan satu lingkungan pada suatu waktu.

Salah satu kopi yang disajikan di Starbucks adalah kopi Arabica yang berasal dari daerah Sumatera, Indonesia. Kopi ini dijadikan bahan utama dalam penyajian kopi di setiap gerai Starbucks (www.kompasiana.com). 
Saat ini dengan memiliki lebih dari 17.000 kedai di 55 negara, menjadikan Starbucks sebagai roaster utama dan peritel kopi spesial di dunia. Dengan setiap cangkirnya, Starbucks berusaha membawa kedua warisannya dan pengalaman yang luar biasa untuk hidup.

\section{Analisis}

Menurut Yasraf (2010) konsumsi diartikan sebagai suatu sistem diferensiasi yakni suatu sistem di mana terjadi pembentukan tingkatan status, simbol dan prestis sosial sebagai tanda hadirnya masyarakat konsumer. Sedangkan dalam masyarakat konsumer yang sudah maju, menurut Willis (1991, 31) konsumsi tidak lagi membutuhkan transaksi atau pertukaran secara ekonomis. Masyarakat mengkonsumsi dengan mata, menginternalisasikannya dan mengkonsumsi komoditas setiap kali masyarakat mendorong troli bolak-balik sepanjang supermarket, atau menonton TV, atau menyetir lewat jalan besar yang menampilkan logo di mana-mana.

Dalam masyarakat konsumer, objek-objek konsumsi dipandang sebagai ekspresi diri atau eksternalisasi para konsumer (bukan melalui kegiatan penciptaan), dan sekaligus sebagai internalisasi nilai-nilai sosial budaya yang terkandung di dalamnya (Yasraf : 148). Dengan berada di Starbucks, sebuah kafe internasional bergaya Barat yang menawarkan berbagai minuman kopi dan snack ala Barat, secara tidak sadar masyarakat merasa diangkat citra dirinya. Yang dikonsumsi masyarakat bukanlah sekedar minuman dan makanan yang ditawarkan di dalamnya tetapi esensi nama besar Starbucks sendiri. Tidak semua masyarakat dari berbagai kalangan dapat mencicipi nikmatnya kopi di Starbucks karena harganya relatif mahal. Maka setiap individu yang berada di dalamya secara tidak langsung menyatakan diri sebagai anggota kelas sosial menengah ke atas dengan acuan tradisi Barat.

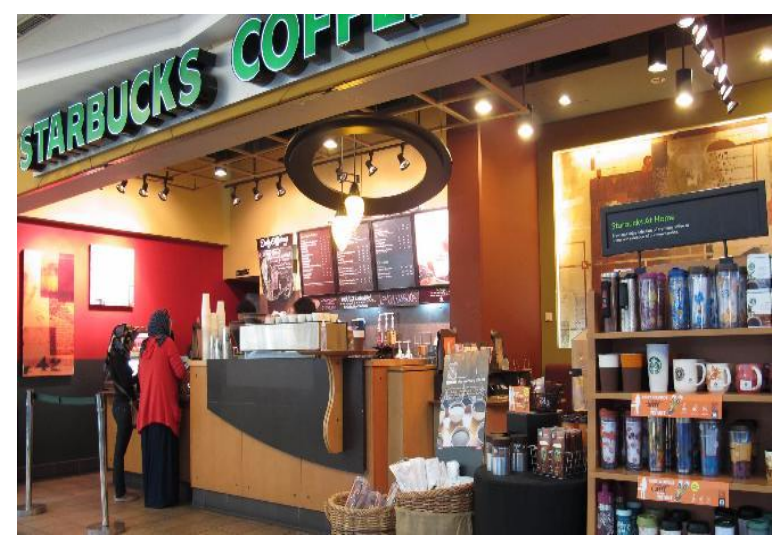

Gambar 2. Starbucks Tunjungan Plaza, Surabaya
Indonesia terkenal dengan biji kopinya yang berkualitas tinggi hingga dapat dinikmati oleh penikmat kopi hampir di seluruh dunia. Masyarakatnya pun memiliki beragam tradisi minum kopi. Salah satu contohnya adalah minum kopi tubruk. Budaya ngopi dengan memasukkan air ke dalam gelas yang sudah berisi bubuk biji kopi. Diamkan beberapa menit, atau silakan diaduk langsung, dan secara konvensional disepakati bahwa ampas dari penyeduhannya tidak dibuang atau dikeluarkan dari gelas, inilah yang dikenal dengan sebutan kopi tubruk (http://jakartavenue. com/2011/07/tradisi-minum-kopi-khas-indonesia/).

Setiap teknik penyeduhan kopi memang mempengaruhi rasa dari kopi itu sendiri. Berbeda dengan kopi tubruk, kopi espresso yang banyak dijual di kafe-kafe dan juga di Starbucks diolah dengan teknologi modern dan paduan topping ala barat yang sangat dibanggakan oleh masyarakat. Dalam hal ini pemaknaan simbolik dari cara pembuatan kopi yang mukhtahir menjadi objek konsumsi masyarakat, bukan mengenai sekedar rasa kopi yang enak. Namun kecenderungan masyarakat kota yang telah dipengaruhi budaya barat menganggap budaya menyeduh kopi seperti halnya minum kopi tubruk sudah ketinggalan jaman. Masyarakat lebih menyukai minum kopi di kedai kopi atau kafe ternama seperti Starbucks yang menyajikan kopi dengan serangkaian alat pembuat kopi yang mukhtahir. Tanpa sadar masyarakat telah masuk dalam budaya urban dan sedikit demi sedikit meninggalkan budaya lokalnya.

Jika kita melihat dari beberapa jenis biji kopi yang disajikan di Starbucks seperti kopi Sumatra, kopi Toraja, Kopi Bali yang tak lain adalah warisan dari hasil kekayaan alam Indonesia seharusnya kita patut berbangga dengan kopi buatan Indonesia. Bukan berpikir sebaliknya dengan mengkonsumsi kopi-kopi ekspreso buatan Itali. Kebanggaan akan budaya lokal seolah sirna oleh kekaguman masyarakat kota terhadap budaya barat yang masuk melalui berbagai media massa yang juga hasil peradaban budaya barat.

Adanya relasi konsumerisme memaknai perilaku masyarakat kota yang lebih senang menikmati kopi di sebuah kafe daripada di rumah sebagai penanda citra diri, kelas atau tingkatan sosial individu tersebut. Dengan harga yang relatif mahal untuk sekedar minum kopi dan makan snack di Starbucks merupakan harga yang harus dibayar masyarakat untuk mendapatkan gengsi atau prestise. Mereka dapat mencitrakan dirinya sebagai konsumer teknologi tinggi, berkelas, berbeda dengan seseorang yang minum kopi tubruk di warung kopi pinggir jalan. Kebanggaan dan 
prestise yang didapat merupakan hiper-realitas dari kenyataan minum kopi tubruk yang ada di pinggir jalan. Perbedaan tempat, teknologi pengolahannya dan cita rasa yang diagungkan di Satarbucks mencairkan kebanggaan masyarakat akan budaya lokal.

Tak terlepas dari citarasa yang diagungkan, konsep Starbucks Coffee yakni berbagi kopi berkualitas dengan sesama (kebersamaan) dan membuat dunia sedikit lebih baik turut berperan dalam relasi konsumerisme masyarakat kota besar di Indonesia. Seperti yang dikatakan Yasraf dalam bukunya Dunia yang dilipat (2010), budaya konsumerisme pada masyarakat konsumer Indonesia dibentuk melalui strategi komunikasi pemasaran. Komunikasi pemasaran Starbucks yang mendengungkan tentang berbagi kopi berkualitas dengan sesama (kebersamaan) dan membuat dunia sedikit lebih baik kepada setiap konsumen terus menerus. Sehingga muncullah suatu persepsi di benak khalayak jika ingin merasakan kebersamaan, santai bersama teman dan membuat dunia lebih baik, minumlah kopi di Starbucks.

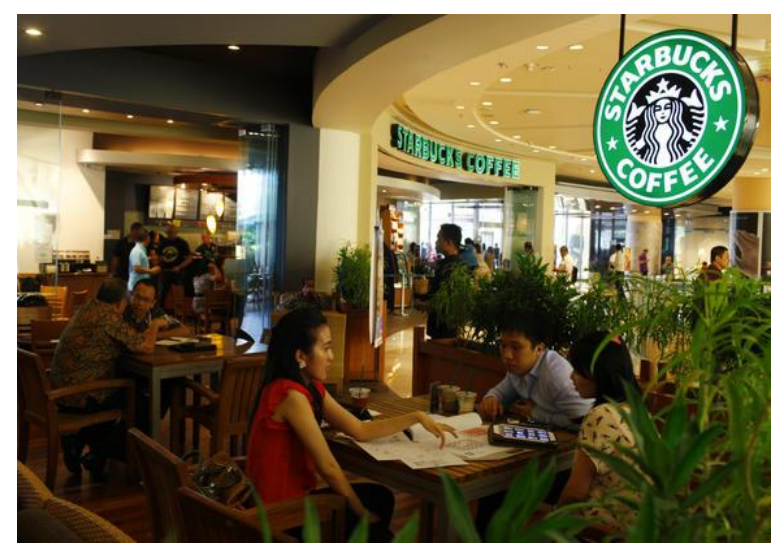

Gambar 3. Kebersamaan di Starbucks Coffee

Strategi komunikasi tersebut direspon cukup baik oleh sebagian besar masyarakat kota besar di Indonesia. Bukan saja untuk bersantai bersama teman atau komunitas tetapi juga merayakan ulang tahun, keberhasilan bahkan melakukan pertemuan kerja (bertemu dengan klien) atau kerja kelompok dilakukan di Starbucks Coffee, seperti yang tercermin pada gambar 3. Tidak menjadi masalah jenis kopi apa yang akan diminum, snack apa yang akan dibeli ketika berada di dalamnnya. Kebersamaan yang didengungkan Starbucks menjadi poin utama yang ingin didapat oleh para konsumen khususnya oleh kalangan muda, baik itu mahasiswa atau pun eksekutif muda. Dalam bukunya, Yasraf (2010) menjelaskan konsumsi sebagai satu fenomena dalam wacana psikoanalisis yakni ketidaksadaran (unconsious). Konsumsi meraih kembali ingatan seseorang tentang rangsangan-rangsangan tak sadar yang dialami pertama kali secara primordial. Kebersamaan bersama keluarga dan temanteman di sekolah yang tak dapat dinikmati kembali karena padatnya pekerjaan dan tuntutan hidup mengakibatkan seseorang ingin menggantikan kesenangan yang hilang tersebut dengan minum kopi bersama komunitas mereka.

Ada semboyan yang berkata "mangan ga mangan asal kumpul" yang berarti makan atau tidak yang penting adalah berkumpul bersama. Hal ini erat sekali dengan kehidupan anak muda saat ini. Yang dijunjung tinggi adalah kebersamaan dalam suatu komunitas tertentu yang bagi mereka menjadi simbol sosial bahwa ia mempunyai relasi tertentu. Kapan pun dan di mana pun para remaja dan kawula muda menginginkan adanya pengakuan dan penghargaan terhadap suatu relasi antara dirinya dengan komunitas yang ia sukai. Sebagai contoh sekelompok mahasiswa yang sengaja belajar bersama di Starbucks Coffee. Kebanggaan akan kepemilikan relasi inilah yang kemudian diaktualisasikan dan dicitrakan melalui kebersamaan minum kopi di Starbucks. Yang dikejar bukanlah belajar bersama atau minum kopi tetapi bagaimana orang-orang di sekitar mereka dapat melihat kebersamaan mereka dan Starbucks menjadi mediumnya. Dengan kata lain Starbucks menjadi medium untuk mencitrakan hubungan atau relasi dari para kawula muda di kota-kota besar.

Kebersamaan terbangun dalam satu medium berupa objek konsumsi. Suatu kenyataan semu yang didapat ketika masyarakat menginginkan kesenangan dan kebersamaan dalam satu ruang dan waktu tertentu yang kemudian lenyap. Kenyataan aslinya atau realitasnya adalah kehidupan sehari-hari di mana para mahasiswa tadi harus kuliah, belajar dan menyelesaikan semua tugasnya. Namun demi kesenangan dan penghargaan secara simbolik terhadap kelas sosial dan pengakuan dari identitas diri para mahasiswa rela mengeluarkan sejumlah uang untuk duduk, menikmati kopi di Starbucks.

Setelah mampu meyakinkan konsumen bahwa Starbucks adalah satu-satunya kafe yang mampu membagikan kopi yang berkualitas dengan kebersamaan, strategi komunikasi pemasaran Starbucks juga merambah bidang merchandise. Beraneka ragam merchandise yang berhubungan dengan menikmati kopi diciptakan, seperti mug putih dengan logo Starbucks yang telah menjadi semacam simbol yang mencitrakan dirinya, botol minum khusus untuk minuman kopi dengan segala desainnya dan sebagainya. 


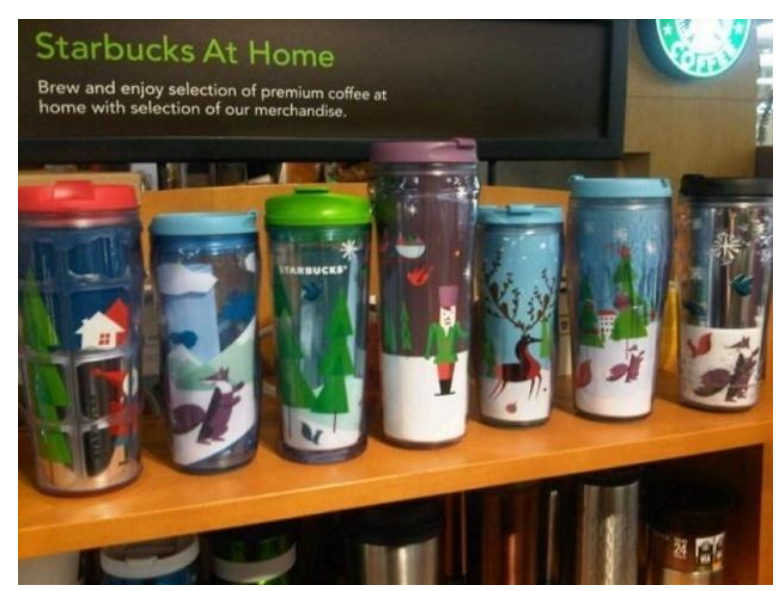

Gambar 4. Merchandise Starbucks Coffee

Merchandise seperti yang nampak pada gambar di atas dirancang khusus agar konsumen dapat membawa pengalaman nikmatnya minum kopi di Strbucks ke rumah, pada saat berpergian dan untuk kebersamaan bersama teman dan keluarga. Konsumen menyadari bahwa kopi terbaik hanya ada di Starbucks, sehingga Starbucks mulai membentuk pola pikir konsumen dalam alam tak sadarnya, bahwa pengalaman menikmati kopi di Starbucks juga dapat dibawa pulang dan dinikmati di rumah. Minum kopi dengan menggunakan mug atau berpergian dengan membawa sebotol minuman kopi yang merupakan merchandise Starbucks akan membawa kenikmatan tersendiri.

Kembali budaya konsumerisme masyarakat dipengaruhi oleh permainan komunikasi pemasaran untuk membentuk suatu gaya hidup yang tanpa sadar dikonsumsi oleh masyarakat konsumer. Konsumer seakan diam dan memposisikan diri dalam relasi subjek-objek, bukan sang pencipta, yang diilustrasikan oleh Yasraf (2010 : 149) layaknya jaring laba-laba, yang menjaring dan mengkonsumsi apa pun yang ada di hadapan mereka.

Sekali lagi kecenderungan hiper-realitas terlihat pada budaya konsumtif masyarakat dengan membeli merchandise untuk membawa pengalaman minum kopi yang terbaik ke rumah. Yang ada hanyalah kopi biasa yang dapat dinikmati di cangkir atau mug. Realitas semu disuguhkan hanya dengan membayangkan berada di Starbucks melalui merchandise yang digunakan. Atau sebuah ilusi yang merubah citarasa kopi biasa menjadi setara dengan kopi di kafe. Jika berpergian atau berkumpul bersama teman dan keluarga di rumah merchandise Starbucks membentuk citra sang empunya di mata orang lain. Menunjukkan kelas sosial, gaya hidup dan prestise seseorang melalui medium merchandise.

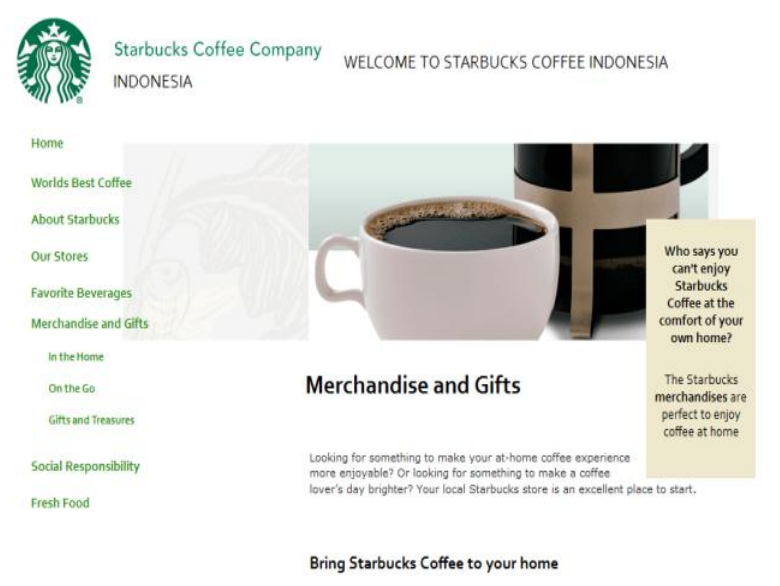

Gambar 5. Halaman Website Starbucks tentang Merchandise

Pada akhirnya budaya konsumerisme masyarakat kota besar di Indonesia dalam kaitannya dengan Starbucks Coffee sebagai objek konsumsi mau mengatakan bahwa objek konsumsi dapat menjadi media hiper-realitas masyarakat kota. Konsumsi tak lagi sebagai satu lalu lintas budaya benda tetapi lebih sebagai panggung sosial yang didalamnya makna-makna sosial diperebutkan. Terjadi perang posisi di antara konsumen yang berada di dalamnya. Semua menginginkan suatu status sosial tinggi dan adanya pengkauan terhadap citra dirinya.

\section{Kesimpulan}

Dari hasil analisis mengenai perilaku konsumerisme masyarakat kota besar di Indonesia terhadap Starbucks coffee sebagai objek konsumsi dapat ditarik beberapa kesimpulan yakni:

- Budaya konsumerisme tak terlepas dari hiperrealitas gaya hidup

- Masyarakat kota besar di Indonesia cenderung membentuk simbol sosial dan identitas kultural melalui produk atau objek konsumsi yang digunakannya (dalam hal ini Starbucks Coffee, bukan sekedar kopinya tetapi nama Starbucks yang dibutuhkan).

- Pengaruh kemuktahiran teknologi dan informasi saat ini mempengaruhi budaya consumerisme masyarakat berkiblat ke tradisi Barat dan menganggap tradisi lokal ketinggalan jaman. Akibatnya budaya lokal pun memudar dan pada akhirnya terjadi kematian budaya lokal.

- Budaya konsumerisme masyarakat kota besar di Indonesia turut dibentuk melalui strategi komunikasi pemasaran suatu produk. Masyarakat mudah sekali mempercayai teks-teks yang mampu meningkatkan status sosialnya.

- Masyarakat menggunakan objek konsumsi sebagai media hiper-realitas yang merupakan objek pengganti kesenangan masyarakat. 


\section{Daftar Pustaka}

Jakarta Veneu (http://jakartavenue.com/2011/07/ tradisi-minum-kopi-khas-indonesia/), diunduh tanggal 20 Desember 2012.

Piliang, Yasraf Amir. (2010). Dunia yang Dilipat: Konsumerisme dan Hiper-Realitas Gaya hidup. Bandung: Matahari.

Piliang, Yasraf Amir. (2010). Dunia yang Dilipat: Terkurung dalam Realitas Semu. Bandung: Matahari.
Starbucks (http://www.starbucks.com/about-us/ourheritage), diunduh tanggal 20 Desember 2012

Starbucks (http://www.starbucks.co.id/en-US/_Merchandise+and+Gifts/), diunduh tanggal 20 Desember 2012.

Lima Tradisi Minum Kopi di Dunia. https://nationalgeographic.co.id/berita/2017/07/lima-tradisiminum-kopi-di-dunia.

Rebellion (26 Februari 2017). Kopi Arabica di Kedai Starbucks. http://www.kopisiana.com/ kopi-arabika-sumatera-di-kedai-starbucks/ 